\title{
PORTUGAL NA ROTA DAS REUNIÕES INTERNACIONAIS DE GEOTURISMO
}

MARIA LUÍSA RODRIGUES ${ }^{1}$

Desde Novembro de 2011 estão disponíveis para consulta, a todos os interessados em geopatrimónio e geoturismo, dois tipos de publicações, resultantes de duas importantes reuniões internacionais realizadas em Portugal.

A primeira é constituída por um Special Issue do GeoJournal of Tourism and Geosites (GTG), coordenado por Maria Luísa Rodrigues, Doriano Castaldini e Enrique Serrano (respectivamente do Instituto de Geografia e Ordenamento do Território da Universidade de Lisboa, do Departamento de Ciências da Terra da Universidade de Modena e Reggio Emilia, e do Departamento de Geografia da Universidade de Valladolid). Este Special Issue do GTG corresponde ao volume 8, 2/2011 e é composto por artigos submetidos por participantes na International Conference on Geoheritage and Geotourism (ICGG2010), realizada em Lisboa entre 14 e 17 de Outubro de 2010.

A segunda publicação corresponde aos Proceedings of the International Congress of Geotourism, coordenados por Daniela Rocha e Artur Sá; a reunião AROUCA2011 realizou-se em Arouca entre 9 e 13 de Novembro de 2011 e a organização optou por editar artigos muito curtos (máximo 4 páginas) e distribuir o volume durante o evento. Os 145 autores das 59 comunicações publicadas, de qualidade muito diversa, são de várias nacionalidades: 92 portugueses (64\% do total), 27 brasileiros (19\% dos autores) e 18 espanhóis (12\% do total). Apenas 8 são autores de outras nacionalidades: 3 da Polónia, 2 da Estónia, 1 da Itália, 1 da Alemanha e 1 da Grécia. A maior parte dos autores de língua não portuguesa estiveram ausentes, tornando desnecessária a tradução simultânea. Saliente-se que 14 dos 59 artigos publicados nos Proceedings, envolveram 35 autores e dedicaram-se a temas relacionados com o geoparque de Arouca.

Pese embora a diversidade das questões, subdivididas em 8 painéis, a discussão central do Congresso acabou por se fixar na definição de Geoturismo e no âmbito do seu conceito, não por força do número de comunicações a este propósito (apenas 2), mas sim devido à conferência de abertura, proferida por Jonathan Tourtellot, que discutiu a abordagem de Geoturismo preconizada pelo National Geographic Centre for Sustainable Destinations (NGCSD). A principal questão colocada pelo orador prendia-se com a necessidade de acrescentar, ou não, à abordagem geográfica do NGCSD, os aspectos geológicos dos lugares. Considerou-se que seria importante não ter em conta apenas os valores geológicos de cada lugar, mas também todos os que constituem o geopatrimónio local (em inglês geoheritage), como os geomorfológicos, hidrológicos, pedológicos, cénicos, ou outros (ver a este propósito a comunicação apresentada por Rodrigues, 2011).

Apesar deste aparente consenso, as comissões organizadora e científica do Congresso AROUCA2011 decidiram apresentar na sessão de encerramento a chamada Declaração de

1 Investigadora do Centro de Estudos Geográficos, TERRiTUR. Instituto de Geografia e Ordenamento do Território, Universidade de Lisboa. E-mail: luisa.rodrigues@campus.ul.pt 
Arouca, onde apenas se refere o papel da geologia e do turismo geológico no geoturismo. Não é de estranhar o realce dado a esta perspectiva "geológica", pois ela é defendida por muitos dos geólogos portugueses e brasileiros (Rodrigues, 2011), em clara maioria neste Congresso, que bem poderia designar-se por Simpósio Luso-Brasileiro de Geoturismo, uma vez que os autores destes dois países correspondiam a $83 \%$ do total. De facto, esta Declaração apenas demonstra uma preocupação relativa à "necessidade de clarificar o conceito de geoturismo", a de indicar que "o turismo geológico assume-se como uma das diversas componentes do geoturismo", sendo os 6 pontos da Declaração dedicados a enaltecer o turismo e o património geológicos. Ou seja, numa reunião sobre geoturismo a Declaração final é parcial e apenas consagrada a uma parte do geopatrimónio. Aliás, como afirmou Ross Dowling (investigador em geoturismo de renome mundial), num comentário efectuado a propósito do artigo elaborado por J. Tourtellot (2011) sobre o Congresso de Arouca, é necessário dar ênfase às "abiotic features of the environment", nomeadamente "the geological elements and landform features", salientando assim, a necessidade de ter em consideração os valores (patrimónios) geológico e geomorfológico.

A International Conference on Geoheritage and Geotourism (ICGG2010), acima referida, também publicou, em simultâneo com a realização da reunião, os respectivos Proceedings, editados por Maria Luísa Rodrigues e Maria Elisabete Freire, onde foram incluídos apenas os resumos alargados das comunicações. Nos 42 resumos aceites estiveram envolvidos 90 autores, oriundos de 16 países, representando 4 continentes: Americano (Brasil, México e Canadá), Africano (Tunísia e Cabo Verde), Asiático (Irão, Índia e China/Taiwan) e Europeu (Portugal, Espanha, França, Itália, Roménia, Suíça, Polónia e Noruega). Os autores de proveniência europeia constituíram uma clara maioria ( $88 \%$ do total), embora os oriundos de Portugal tenham representado apenas $28 \%$ do total, sendo 5 dos 25 autores portugueses originários dos Açores. As participações italiana e romena envolveram, respectivamente, 16 e 15 autores, e a espanhola integrou 10 investigadores, 5 dos quais provenientes das ilhas Canárias. A presença de investigadores ligados ao Centro de Estudos Geográficos e ao Instituto de Geografia e Ordenamento do Território da Universidade de Lisboa foi muito significativa, uma vez que dos 42 resumos dos Proceedings da ICGG2010, aqueles investigadores participaram em 9, com o mesmo número de comunicações.

$\mathrm{O}$ facto de os autores europeus serem maioritários na International Conference on Geoheritage and Geotourism (ICGG2010), acabou por se reflectir nos artigos publicados no Special Issue do GeoJournal of Tourism and Geosites, 2/2011, IV (8). Neste número há 14 artigos de diferente dimensão, dedicados a áreas dos seguintes países: 4 de Espanha (incluindo 1 das Canárias), 3 da Roménia e de Portugal e 1 de cada um dos seguintes países: França, Itália, Noruega e Cabo Verde.

Os principais assuntos dizem respeito à valorização dos elementos abióticos e sua aplicação como recursos geoturísticos. Em 6 artigos discutem-se abordagens ao geoturismo e em 4 tratam-se os mapas geoturísticos. Apenas 3 artigos estão mais relacionados com o geopatrimónio e 2 com o património geológico. Assuntos como a geodiversidade e os geoparques são mencionados num artigo. Saliente-se que as investigações sobre a geodiversidade e o geopatrimónio dizem normalmente respeito a áreas rurais, mas neste volume há um par de artigos centrados em Lisboa (Portugal).

Os três principais temas discutidos neste volume especial (a geodiversidade, o geopatrimónio e o geoturismo), não receberam atenção equitativa, reflectindo perfeitamente o que se passou na Conferência. As questões relacionadas com a geodiversidade foram as menos desenvolvidas, quando comparadas com o destaque conferido às questões geopatrimoniais. 
O geopatrimónio foi considerado como um todo, ou referenciado apenas através das suas componentes, como é o caso dos patrimónios geológico e geomorfológico, ou dos elementos que representam este último, isto é, os geomorfossítios. Contudo, a promoção do património geomorfológico e dos geomorfossítios, inventariados e classificados em diferentes áreas e a diferentes escalas, foi sempre relacionada com o desenvolvimento geoturístico dessas áreas. Para alcançar o desenvolvimento sustentável local, usando abordagens geoturísticas, alguns autores recomendaram a elaboração de mapas geoturísticos, que podem ser concebidos utilizando distintos métodos, conteúdos e símbolos.

\section{BIBLIOGRAFIA}

Rocha D, Sá AA (Coords.) (2011) Proceedings of the International Congress of Geotourism, AROUCA2011.Arouca, Portugal.

Rodrigues M L (2011) The scope of geotourism. In Rocha D, Sá, AA (Coords.), Proceedings of the International Congress of Geotourism, AROUCA2011 (.), Arouca, Portugal: 101-104.

Rodrigues M L, Freire E (eds.) (2010) Proceedings of the International Conference on Geoheritage and Geotourism, Lisbon. APGeoturand CEG-UL, Lisboa, Portugal.
Rodrigues M L, Castaldini D, Serrano E (Coords.) (2011) GeoJournal of Tourism and Geosites, special issue, 2/2011, IV(8). http://gtg.webhost.uoradea.ro/

Tourtellot J (2011) National Geographic, Daily News, 17 November 2011.http://newswatch. nationalgeographic.com/2011/11/16/unesco $\%$ E2\%80\%99s-\%E2\%80\%9Cgeoparks\% E2\%80\%9D-embrace-geotourism/?mid=52 [Acedido em 18 de Novembro de 2011].

\section{ENCONTRO ANUAL DA ASSOCIAÇÃO AMERICANA DE GEÓGRAFOS 2011 RETROSPECTIVA TEMÁTICA E APRENDIZAGENS}

O encontro anual da associação americana de geógrafos é uma das maiores reuniões da ciência geográfica ao nível mundial. A sua organização em formato semanal, intercala sessões de apresentação, com painéis de debate, workshops, feira de emprego em geografia,

1 Núcleo TERRiTUR (Turismo, Cultura e Território), Centro de Estudos Geográficos, IGOT; albino.sara@gmail.com; diana-almeida@campus.ul.pt

2 Núcleo MOPT (Modelação, Ordenamento e Planeamento do Território), Centro de Estudos Geográficos, IGOT; joaofumega@gmail.com 